\title{
Continuous mandibular nerve block for pain relief. A report of two cases
}

\author{
[Analgésie par blocage continu du nerf maxillaire inférieur. Étude de deux cas.]
}

Baljit Singh MD, Vinay Bhardwaj DA

Purpose: Mandibular nerve block allows surgery to be performed on the mandible. However, pain in the postoperative period needs to be treated with opioids or non-steroidal anti-inflammatory agents which have undesirable side effects. We examine the feasibility of continuous mandibular nerve block with $0.25 \%$ bupivacaine top-ups using a catheter for intraoperative and postoperative pain relief in two patients with a fracture of the mandible.

Methods: Using the lateral extraoral approach, the mandibular nerve was approached with an 18-gauge indwelling iv cannula in two patients undergoing repair of a fractured mandible under general anesthesia. After removing the needle, an I8-gauge epidural catheter was inserted into the cannula which was then removed. The catheter was tunnelled subcutaneously to emerge at the lateral aspect of the forehead. Two to $4 \mathrm{~mL}$ bupivacaine $0.25 \%$ were injected on a 12-hr basis and the catheter was kept in place for seven days.

Results: Both patients had excellent pain relief and no parenteral or oral analgesics were required throughout the postoperative period. No side effects were noted.

Conclusions: Continuous mandibular nerve block with 2-4 mL $0.25 \%$ bupivacaine top-ups injected twice a day through a catheter provides excellent pain relief in patients with a fracture of the mandible. This method may have implications for the management of pain of other etiology in the mandibular region.

Objectif : Le blocage du nerf maxillaire inférieur permet de procéder à une intervention chirurgicale mandibulaire. Cependant, la douleur postopératoire doit être traitée avec des opioïdes ou des anti-inflammatoires non-stéroïdiens qui présentent des effets secondaires indésirables. Nous avons vérifié la faisabilité d'un blocage continu du nerf maxillaire inférieur avec des doses d'appoint de bupivacaïne à 0,25 \% au moyen d'un cathéter pour l'analgésie peropératoire et postopératoire chez deux patients victime d'une fracture de la mandibule.

Méthode : Le nerf maxillaire inférieur a été atteint, en utilisant une approche extra-orale, avec une canule iv à demeure de calibre 18 chez deux patients devant subir la réparation d'une fracture de la mandibule sous anesthésie générale. Après le retrait de l'aiguille, un cathéter péridural de calibre 18 a été inséré dans la canule qui a été enlevée. Le cathéter a été tunnellisé par voie sous-cutanée pour ressortir à la face latérale du front. De 2 à $4 \mathrm{~mL}$ de bupivacaïne à $0,25 \%$ ont été injectés aux $12 \mathrm{~h}$ et le cathéter a été maintenu en place pendant sept jours.

Résultats : Les deux patients ont reçu une excellente analgésie et aucun analgésique postopératoire parentéral ou oral n'a été demandé. Aucun effet secondaire r'a été noté.

Conclusion : Le blocage continu du nerf maxillaire inférieur avec des doses d'appoint de 2-4 mL de bupivacaïne à 0,25\% injectés deux fois par jour par un cathéter fournit une excellente analgésie aux patients opérés pour une fracture de la mandibule. Cette méthode a des implications sur la gestion de la douleur d'autre source dans la région mandibulaire.

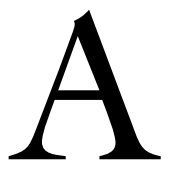
mandibular nerve block is often performed for diagnostic, therapeutic and anesthetic purposes for surgery involving the mandibular region. ${ }^{1}$ Advantages of a nerve block include excellent pain relief and avoidance of the side effects associated with the use of analgesics. We report the technique of continuous mandibular nerve block for pain relief in two patients who underwent surgery for repair of a fractured mandible.

\section{Case 1}

A 74-yr-old, $52 \mathrm{~kg}$, male with gun-shot injury to the face with fracture of the left ramus of the mandible, was scheduled for an elective open reduction and internal fixation. The patient had difficulty opening the mouth $(3 \mathrm{~cm}$, best effort) due to pain. Surgery was planned under general anesthesia with a continuous mandibular nerve block for intraoperative and postoperative analgesia. The patient was familiarized with the visual ana-

From the Department of Anaesthesiology, Lady Hardinge Medical College and Associated Hospitals, New Delhi, India. Address correspondence to: Dr. Baljit Singh, Associate Professor, Department of Anaesthesiology, Lady Hardinge Medical College and Associated Hospitals, New Delhi 110 001, India. E-mail: dr_baljit@yahoo.com or rasvin666@rediffmail.com Accepted for publication May 17, 2002.

Revision accepted August 14, 2002. 


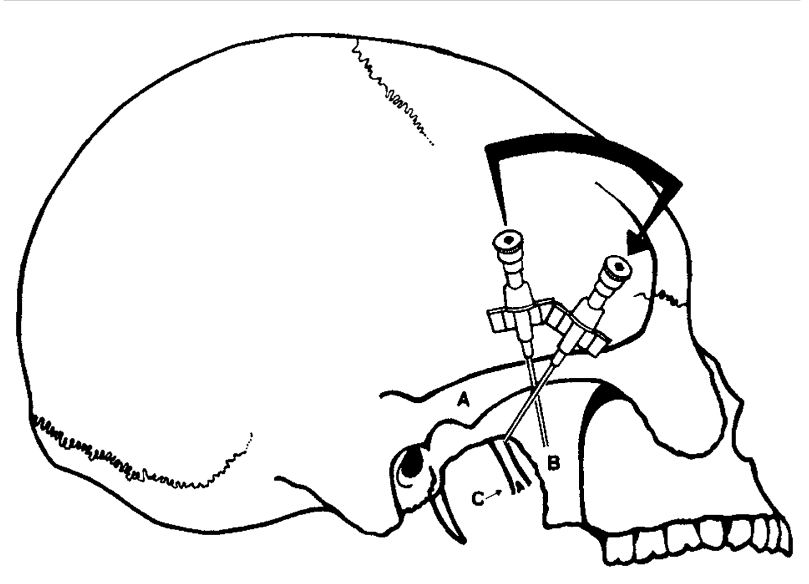

FIGURE 1 The $i v$ cannula on reinsertion contacting mandibular nerve. A) zygomatic arch; B) lateral pterygoid plate; C) mandibular nerve.

logue scale (VAS) of 0-10. After giving informed consent, anesthesia was induced with thiopentone and orotracheal intubation was facilitated with succinylcholine. Neuromuscular blockade was achieved with vecuronium and anesthesia was maintained with $\mathrm{O}_{2}$ and $\mathrm{N}_{2} \mathrm{O}$ using controlled ventilation. The left side of the face was prepared for the block with the extraoral lateral approach. An 18-gauge indwelling iv cannula was inserted at the midpoint of the lower border of the zygomatic arch and advanced perpendicular to the face until it contacted the lateral pterygoid plate. The length of the cannula outside of the skin was marked and the cannula was withdrawn and redirected slightly posteriorly to reach behind the posterior border of the lateral pterygoid plate (Figure 1).

Once the marked length was reached without contacting the bone indicating its passage behind the posterior border of the lateral pterygoid plate, it was advanced further by $0.5 \mathrm{~cm}$. The needle from the cannula was removed and an 18-gauge epidural catheter (B.Braun, Melsungen AG, Germany) was threaded into the cannula (Figure 2A) which was then removed maintaining inward pressure on the epidural catheter. It was then tunnelled $s c$ to emerge at the lateral aspect of the forehead and fixed there with a filter (Figure 2B). A bolus dose of $4 \mathrm{~mL}$ of $0.25 \%$ bupivacaine was injected through the catheter and the surgeon was allowed to proceed. Surgery lasted about two hours and no opioids were given in the intraoperative period. After surgery, a top-up dose of $3 \mathrm{~mL}$ of $0.25 \%$ bupivacaine was given and neuromuscular blockade was reversed. Following extubation, the patient was conscious and

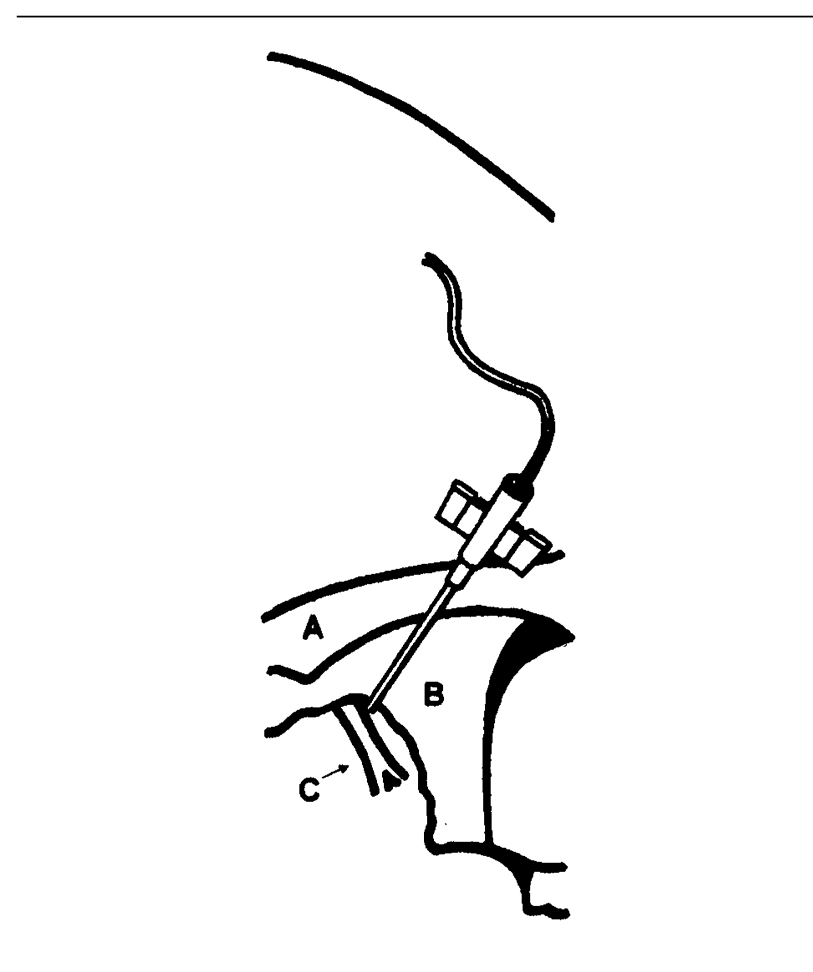

FIGURE 2A Epidural catheter inserted into the iv cannula after removing the needle.

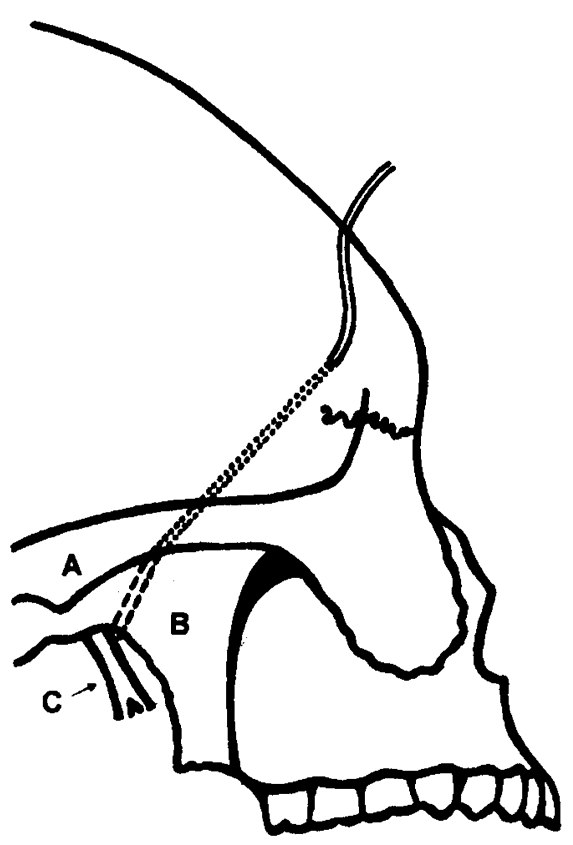

FIGURE 2B Cannula removed and catheter tunneled $s c$. 
pain free and was moved to the recovery room. In the evening the pain score on the VAS was measured as ' 1 '. A top-up dose of $4 \mathrm{~mL}$ of $0.25 \%$ bupivacaine was given at night and repeated every $12 \mathrm{hr}$ for two days. Thereafter, the regimen of 12-hr top-ups was changed to $3 \mathrm{~mL}$ for two days and $2 \mathrm{~mL}$ for the next three days. Pain was measured before every top-up. The maximum pain score noted throughout the postoperative period was ' 2 ' on one occasion on the second day. On the seventh day, to assess the need to continue top-up administration, the evening dose was omitted. The next morning, pain was measured to be ' $\mathrm{l}$ '. The catheter was then removed and no evidence of infection at the exit site and subcutaneous track was noted. There was no motor or sensory deficit in the mandibular region and the patient was discharged on the tenth day.

\section{Case 2}

A 53-yr-old male was scheduled for open reduction and fixation of a fracture of the left ramus of the mandible sustained during a fight. After giving informed consent, anesthesia was induced and, using an 18-gauge iv cannula, the injection port end of an 18-gauge epidural catheter was inserted as in case 1 and $4 \mathrm{~mL}$ of $0.25 \%$ bupivacaine were injected. Surgery lasted one hour and $25 \mathrm{~min}$ and no analgesic was given intraoperatively. One hour after surgery the pain score was noted to be ' 2 ' and the patient could open his mouth and talk without any difficulty. A top-up of $3 \mathrm{~mL} 0.25 \%$ was given at night, was continued every $12 \mathrm{hr}$ subsequently and reduced to $2 \mathrm{~mL}$ after two days. VAS scores noted before every top-up remained between ' $0-2$ ' throughout the postoperative period. On omitting a dose on the seventh day, no increase in pain score was noted and the catheter was removed. There were no complications and the patient was discharged on the eighth day.

\section{Discussion}

Mandibular nerve blocks can be easily performed by the lateral extraoral approach ${ }^{1}$ or by the intraoral approach. The lateral extraoral approach was preferred because our patients had difficulty in opening the mouth and also because we planned to place a catheter for postoperative analgesia. We used an 18-gauge iv cannula to place the epidural catheter instead of a Tuohy needle (which has a large tip), to minimize possibility of bleeding from the pterygoid plexus of veins.

In case 1 , the cannula was advanced by an additional $0.5 \mathrm{~cm}$ over the pre-measured distance from the skin to the lateral pterygoid plate. This increase is not required to reach the mandibular nerve, ${ }^{2}$ but was destined to bring the most distal eye of the epidural catheter, which is about $0.5 \mathrm{~cm}$ from the tip, as close to the nerve as possible. In case 2 , no further advance of the cannula was necessary as the catheter was inserted from the opposite end (injection port end) which has no lateral eyes. The catheter was tunnelled $s c$, away from the surgical field, and the filter was used to minimize the risks of infection.

Open reduction and internal fixation can be done using a single-shot mandibular nerve block, but the need for opioids or non-steroidal anti-inflammatory drugs to relieve pain may result in adverse effects, negating the benefits of surgery conducted under local anesthesia.

In conclusion, we performed continuous mandibular nerve blocks using bupivacaine $0.25 \%$ injected through an 18-gauge epidural catheter placed via an 18-gauge iv cannula. The block was easy to perform and provided adequate intraoperative and postoperative analgesia. This technique may prove to be useful in the management of pain of other etiology in the mandibular region.

\section{References}

1 Wedel DJ, Brown DL. Nerve blocks. In: Miller RD (Ed.). Anaesthesia, $3^{\text {rd }}$ ed. London, England: Churchill Livingstone, 1990: 1426.

2 Singh B, Srivastava SK, Dang R, Gombar KK, Gombar $S$. Anatomic considerations in relation to the mandibular nerve block. Reg Anesth 1993; 18: 181-3. 